\title{
A produção musical autoral e independente na cidade de Vitória-ES e o novo espírito do capitalismo
}

\author{
Manuela Vieira Blanc ${ }^{1}$ \\ Fabio Rodrigues ${ }^{2}$
}

\section{Resumo}

Este artigo analisa os dados coletados em uma pesquisa de inspiração etnográfica e visa compreender a lógica discursiva de músicos independentes atuantes na cidade de Vitória - ES. Para tanto, articula dados obtidos ao longo dos últimos seis anos e que mapearam os processos de atuação de empreendedores culturais, a conformação de um circuito de promoção do empreendedorismo local e as falas públicas proferidas por músicos autorais independentes capixabas sobre o seu contexto de atuação. Acompanhamos ao longo dos últimos quatro anos mudanças nos discursos dos produtores culturais atuantes no Centro da cidade de Vitória, capital do Estado do Espírito Santo, e que refletem transformações na avaliação de suas condições de atuação, transferindo do poder público para si mesmos o protagonismo em fazer acontecer. Do mesmo modo, observamos nas falas dos músicos autorais atuantes nesse contexto a reprodução de uma lógica discursiva que, mais do que problematizar as dificuldades vividas no exercício da sua profissão como parte de um processo mais amplo de transformações do mercado fonográfico (marcado pela precarização das suas condições de trabalho), ou a insuficiência das políticas culturais como subsídio à produção musical local, reproduzem o discurso de responsabilização individual pelo sucesso dos seus projetos profissionais. Deste modo, destacamos a emergência de uma lógica liberal dos interesses individuais no contexto cultural local, bem como a capacidade adaptativa dos atores em se ajustar aos sistemas normativos em vigência, produzindo estratégias e fazendo articulações em favor da construção das suas carreiras. Os desafios em torno da produção musical local são colocados a partir das dificuldades experimentadas no cotidiano das suas práticas profissionais, as assimetrias de condições sendo problematizadas em nível micro, dificultando a possibilidade de articulação para além de um espectro do próximo.

\section{Palavras-chave}

Empreendedorismo cultural. Ator por projeto. Produção musical independente. Gramática liberal dos interesses individuais.

\footnotetext{
${ }^{1}$ Doutora em Sociologia Política pela Universidade Estadual do Norte Fluminense Darcy Ribeiro. E-mail: manuela.blanc@ufes.br.

2 Mestre em Sociologia Política pela Universidade Vila Velha. E-mail: binhoinforms@yahoo.com.br.
} 


\section{Abstract}

This article analyzes the data collected in an ethnographic-inspired research and aims to understand the discursive logic of independent musicians working in the city of Vitoria ES. For this, it articulates the data obtained over the last six years and which mapped the performance processes of cultural entrepreneurs, the formation of a circuit to promote local entrepreneurship and the public speeches given by independent musicians from Espírito Santo about their context of performance. Over the past four years, we have followed changes in the discourses of cultural producers working in downtown Vitória, capital of the Espírito Santo state, which reflect changes in the assessment of their operating conditions, transferring the leading role of making it happen from the public authorities to themselves. Likewise, we observe in the speeches of musicians working in this context, the reproduction of a discursive logic that, more than problematizes the difficulties experienced in the exercise of their profession as part of a broader process of transformation in the phonographic market (marked by the precariousness of their working conditions), or the insufficiency of cultural policies as a subsidy to local music production, reproduce the discourse of individual responsibility for the success of their professional projects. Thus, we highlight the urgency of a liberal logic of individual interests in the local cultural context, as well as the adaptive ability of actors to adjust to the normative systems in force, creating strategies and making articulations in favor of building their careers. In this way, the challenges surrounding the local music production are posed from the difficulties experienced in the daily life of their professional practices, the asymmetries of conditions being problematized on the micro level, hindering the possibilities of an articulation beyond a spectrum of the next.

\section{Keywords}

Cultural entrepreneurship. Actor by project. Independent music production. liberal grammar of individual interests.

O presente artigo analisa os dados coletados em uma pesquisa de inspiração etnográfica desenvolvida no âmbito do grupo de pesquisa Cidades, Espaços Públicos e Periferias (Cep 29) e visa compreender o processo de ascensão de uma lógica discursiva liberal $^{3}$ entre músicos independentes atuantes na cidade de Vitória - ES ao longo dos últimos anos, passível de ser enquadrada no contexto de um novo espírito capitalista, segundo o sentido que lhes conferem

\footnotetext{
3 Caracterizado como reconfiguração ideológica associada às transformações do mundo econômico, o liberalismo será pensado a partir dos recursos motivacionais que mobilizam a força de trabalho, tendo a flexibilização da vida, a partir da flexibilização dos modos de produção, um núcleo ideológico característico dos novos tempos, alterando as formas de organização do mundo do trabalho (BOLTANSKI; CHIAPELLO, 2006 apud PRESTIFLIPPO; WEGELIN, 2016).
} 
Luc Boltanski e Éve Chiapello (2009). Interessa-nos compreender, por outro lado, os processos de ajustamento, negociação e articulação assumidos por esses atores como estratégias na construção das suas carreiras.

Segundo os autores, estaríamos vivendo um terceiro momento do capitalismo. Marcado por uma lógica moral emergente ao longo das últimas décadas, que reconhece a volatilidade dos processos de produção, bem como das conexões que os envolvem, para além dos sistemas produtivos centralizados por empresas, esse novo espírito capitalista é caracterizado pela descentralização dos processos produtivos. As críticas direcionadas ao sistema capitalista, segundo os autores, teriam o papel de impulsionar transformações em seu interior em termos de justificações que possibilitem a sua efetivação, apesar das suas contradições.

No contexto atual, esse processo se dá pela valorização de um novo tipo de ator social, não mais estimulado pelas promessas de estabilidade profissional, demandante da assistência estatal ou vinculado institucionalmente a uma empresa, igualmente passível de ser cobrada pela garantia das suas condições de produção. O profissional que emerge no tempo presente é motivado por um novo espírito, que toma para si a responsabilidade pelo próprio sucesso, ao mesmo tempo que precisa desenvolver capacidades adaptativas que lhe permitam manter a competitividade em uma lógica de mercado altamente flexível. Esse é o ator por projeto, um profissional cuja especialização é a própria adaptabilidade, bem como a capacidade de estabelecer comunidades em rede, fontes de parcerias profissionais voltadas para responder a demandas pontuais do mercado (BOLTANSKI; CHIAPELLO, 2009).

Ao mesmo tempo, as relações estabelecidas entre os atores em tal contexto serão marcadas por uma gramática liberal de interesses, expressa em engajamentos individuais por "escolhas" realizadas por indivíduos autônomos entre opções de conhecimento comum (THÉVENOT, 2019, grifos do autor). Interessa-nos refletir, a partir dos dados aqui acionados, como os interesses expressos, apesar de restritos em relação às concepções de bem comum, se legitimam em negociações de bem compartilhados em dado contexto, ou em um bem de todos (WERNECK, 2012) os envolvidos em dado campo de disputa. Deste modo, "people transform intimate experiences, personal grievances or scattered observations into a more general format that facilitates coordination with others using categories, conventions, customs, standards, methods, etcas" (THÉVENOT, 2019, p. 225).

${ }^{4}$ Pessoas transformam experiências íntimas, queixas pessoais ou observações dispersas em um formato mais geral que facilita a coordenação com outras pessoas usando categorias, convenções, 
Acompanhamos ao longo dos últimos quatro anos mudanças nos discursos dos produtores culturais atuantes no Centro da cidade de Vitória, capital do Estado do Espírito Santo, e que refletem transformações na sua capacidade crítica de avaliar suas condições de atuação. Em um primeiro momento de coleta de dados, que culminou na produção do trabalho de Néspoli (2016), os empreendedores culturais do Centro se referiam às suas condições de trabalho em caráter crítico, denunciando o que então consideravam negligência do poder público, municipal e estadual, no fomento à produção cultural local. Mais recentemente, esses atores vêm se posicionando como multiplicadores em projetos de promoção de uma cultura criativa, marcada pela ideia de que a iniciativa individual e as conexões em redes são o impulso para a realização das transformações desejadas, força de concretização dos projetos coletivos, assumidos como responsabilidade dos atores individuais envolvidos.

A ascensão dessa lógica discursiva foi gestada progressivamente nesse contexto através de iniciativas que articulam ações envolvendo poder público e privado, mas que se efetivam, entre nossos interlocutores, como reflexo do seu potencial empreendedor, como um produto espontâneo da sua articulação, na composição de redes que os conectam em prol do que, mais recentemente, denominam reavivamento cultural do Centro de Vitória, capital do Estado do Espírito Santo.

Uma série de atividades foram promovidas em Vitória ao longo dos últimos anos sob a roupagem capacitação para o empreendedorismo. Os interlocutores de pesquisa de Ramos (2018), membros de um núcleo de promoção do consumo sustentável criado na cidade no ano de 2016, apontam para o Programa de Empreendedorismo promovido pela Shell Brasil como referência ao seu processo de capacitação para a gestão de seus negócios na cidade. O curso, realizado em parceria com o Centro Integrado de Estudos e Programas de Desenvolvimento Sustentável - Cieds, visou à formação, ao suporte e ao estímulo para que empreendedores possam desenvolver seus próprios negócios no setor de óleo e gás por meio de relacionamentos sustentáveis (IFES, 2013) e é citado por esses atores como a base da lógica justificadora de suas ações, como a criação do Núcleo BeijaFlor, que teria como objetivo, entre outras coisas, manter conectada a rede dos participantes deste programa (vide RAMOS, 2018).

A realização do Dia Mundial da Criatividade, no mês de abril de 2018, em Vitória, articulou de modo remarcável os empreendedores culturais atuantes no Centro da cidade, anteriormente entrevistados por Néspoli (2016), além de

costumes, padrões, métodos etc. (tradução nossa). 
outros sujeitos que vêm sendo acompanhados no âmbito do grupo de pesquisa ao longo dos últimos anos. Promovendo localmente atividades que compõem uma iniciativa internacional e chancelado pela ONU, o evento foi realizado em parceria com a Secretaria de Estado da Cultura, a Secretaria de Estado de Gestão e Recursos Humanos (Serger), o Sebrae e a Companhia de Desenvolvimento de Vitória, com apoio da Secretaria Municipal de Inovação e Tecnologia da cidade de São Paulo, e realizado sob a liderança da multiplataforma de valorização do ES, denominada Espírito Criativo ${ }^{5}$.

Na prática, estabelecimentos comerciais e de lazer locais foram convidados, através de seus gestores, personagens atuantes na cena cultural do Centro e cujas ações já vinham sendo objeto de observação no âmbito do nosso grupo de pesquisa, a promover debates, atividades culturais e workshops em seus espaços, articulando suas redes pessoais e recursos próprios (com exceção do material de divulgação do evento e a infraestrutura básica para a sua realização, como o acesso à plataforma virtual para realização das inscrições e envio dos certificados).

Criatividade, inovação e empreendedorismo foram as palavras de ordem, acionadas no conjunto das atividades promovidas. O desenvolvimento de habilidades individuais (controle emocional, desbloqueio criativo, prática de comunicação não violenta, entre outros exemplos), o debate do contexto local e seus condicionantes para as iniciativas em movimento, o aprendizado de técnicas de gerenciamento de novos modelos de negócios e atividades, cujo fim declarado é a composição de redes de profissionais em torno de atuação e interesses comuns, caracterizam as diferentes ações propostas nas mais diversas atividades da programação ${ }^{6}$.

Nossos antigos interlocutores de pesquisa, até então público-alvo das oficinas de empreendedorismo promovidas na cidade, assumem, a partir dessa iniciativa, o papel de multiplicadores desses valores, cooptados por uma nova ordem de justificação das suas ações, bem como por novas modalidades de agenciamento das limitações enfrentadas em seu contexto de atuação.

Se em Néspoli (2016) vemos essas personagens atribuindo ao poder público a responsabilidade por garantir o sucesso de suas iniciativas individuais, percebidas ainda como atitudes altruístas de busca por um bem comum, que justifica e dá sentido aos seus engajamentos individuais, apesar das

\footnotetext{
${ }^{5}$ Entidade que assume ou integra a equipe de promoção de algumas dessas atividades que compõem o que denominaremos circuito de promoção do empreendedorismo local.

${ }^{6}$ Disponível em https://www.worldcreativityday.com/world/atividades, Acesso em: julho de 2019.
} 
dificuldades, a partir desse momento pudemos observá-los em outra posição. Empreender é a palavra do momento, e a esse ator por projeto, desamparado estatal e institucionalmente (nos mesmos moldes com que nos destacam Boltanski e Chiapello, 2019), cabe a garantia do seu próprio sucesso (bem como da realização dos projetos aos quais estão engajados).

Diversas iniciativas semelhantes foram realizadas em Vitória, acompanhando uma tendência (inter)nacional: desde atividades que partem declaradamente da iniciativa privada àquelas promovidas diretamente pelo poder público local, através de suas secretarias de Estado, ou as que envolvem a interpelação dos próprios atores individuais, empreendedores locais, na promoção de atividades que valorizam ou incentivam iniciativas identificadas com essa lógica argumentativa.

Outro evento que foi objeto de observação no âmbito do "projeto CEP 29: Núcleo capixaba de estudos da experiência humana em meio urbano" ${ }^{7}$ foi a primeira edição do Formemus, realizado entre os dias 22 e 25 de maio de 2018, no Palácio da Cultura Sônia Cabral (Centro de Vitória/ES). Essa atividade teve como objetivo, segundo o material informativo distribuído na entrada do evento, "proporcionar um espaço de discussão a respeito de novos modelos de mercado e distribuição de música, além de ser um encontro para dialogar a música de forma enriquecedora, colaborativa, sustentável e criativa".

O Palácio da Cultura Sônia Cabral, inaugurado em 2016 como homenagem à pianista Sônia Cabral, fundadora da Orquestra Filarmônica do Espírito Santo e diretora da Faculdade de Música do Espírito Santo (Fames), é um espaço integrante do "Programa de Preservação e Revitalização do Patrimônio Cultural e também faz parte do Plano Estratégico de Ação e Política Cultural do Governo do Estado, desenvolvido pela Secretaria de Estado da Cultura" (SECULT, 2019). O local é, desde então, um espaço estratégico do ponto de vista simbólico-moral relacionado à música, como também uma referência para projetos culturais relacionados a novos modelos de negócios na cidade.

Poucas semanas antes dessa edição do Formemos, esse espaço sediou ainda uma das atividades da Virada Turística Capixaba, ação de iniciativa pública e privada entre a Secult e o Sebrae, envolvendo a promoção do empreendedorismo sob a forma de uma agenda de capacitação de empreendedores individuais e palestras sobre criatividade e inovação. A partir do trabalho de Breviglieri (2021, p. 401), é possível compreender como essas iniciativas espelham um "modelo de governança [que] é capaz de se apoiar em

${ }^{7}$ Coordenado por Manuela Vieira Blanc. 
mecanismos que encorajam, de certa maneira, a iniciar um movimento de crítica" (BREVIGLIERI, 2021, p. 401), incluindo em suas programações espaços para a discussão dos problemas enfrentados pelos empreendedores culturais locais e a proposição de possíveis soluções. Por outro lado, esse exercício crítico é concebido do interior do sistema e não em ruptura com ele, assim como o observado pelo autor, promovendo uma forma de civilidade liberal e a legitimação das práticas de gestão a partir de uma suposta participação popular.

É interessante observar como, desde o Dia Mundial da Criatividade, a presença de produtores musicais locais é remarcada como parte da programação dessas diferentes atividades que compõem o circuito de promoção do empreendedorismo local em Vitória.

Destacamos neste artigo como esses atores reproduzem o discurso de responsabilização individual, característico de uma ordem neoliberal, ou do novo espírito do capitalismo, apontado por Boltanski e Chiapello (2009), orientando-se em conformidade com o contexto e buscando "os meios de reforçar suas capacidades de autodeterminação" (BREVIGLIERI, 2021, p. 395).

Os eventos observados ao longo do Formemus, decorridos apenas dois meses do Dia Mundial da Criatividade, também apontam para uma intensificação desse discurso nas falas dos artistas presentes.

Destacamos como, em todas as situações observadas, o protagonismo dos atores (categoria acionada por eles para se posicionar publicamente) é amparado pelo apoio de órgãos públicos e empresariais exclusivamente no que se refere ao apoio aos eventos de formação no interior desse circuito de promoção do empreendedorismo local. Esses órgãos estatais, agora apoiadores de iniciativas empreendedoristas, são aqueles mesmos anteriormente criticados por nossos interlocutores (em NÉSPOLI, 2016) como negligentes no processo de requalificação do bairro em que atuam, no que se refere às políticas culturais de valorização do Centro de Vitória.

Sob as noções de protagonismo e empoderamento, esses atores empreendedores culturais assumiram, ao longo do tempo, o papel de promotores de uma lógica de mercado marcada pela flexibilização das relações trabalhistas, a ausência de amparo estatal (seja no que se refere a uma atuação mais direta nos processos de requalificação do bairro e da cidade, seja em iniciativas especificamente voltadas para a produção cultural local) e a superacumulação de capital pelos grandes aglomerados empresariais. Se a sua crítica a essas instâncias governamentais colocava em questão, três ou quatro anos antes, o seu compromisso em assumir o seu papel social, agora esses 
atores se unem ao Estado para promover o redirecionamento da responsabilidade pelo sucesso dessas iniciativas aos atores individuais - eles mesmos.

Ao mesmo tempo que estão em jogo ao longo de todo o nosso trabalho de observação práticas individuais de engajamento em plano, observamos a reconfiguração do ambiente de atuação em função da coordenação das ações entre os envolvidos. Cientes de que esse ambiente ajuda a reforçar esse engajamento, uma vez que o ordena, observamos como o engajamento desses atores em seus projetos individuais, em primeira instância, é reflexo da emergência e motor de consolidação de uma gramática liberal de interesses individuais (THÉVENOT, 2019).

Para o desenvolvimento deste artigo, faremos um recorte metodológico, partindo especificamente dos dados obtidos em uma pesquisa que toma a cena musical capixaba ${ }^{8}$ independente como objeto (RODRIGUES, 2019). As estratégias que esses artistas acionam para lidar com o processo de gestão de suas carreiras bem como as articulações que realizam na busca pelo sucesso e o modo como se posicionam no contexto de produção cultural local são exemplares entre os possíveis para que pensemos os modos como esses atores se articulam, no interior dessa ordem de grandeza, para agir em comum e em favor das suas carreiras.

Inseridos nessa dinâmica de promoção de iniciativas empreendedoras, criativas e inovadoras na cidade, eles são alvo e motor de efetivação de atividades especificamente voltadas ao mercado musical local, bem como integram os demais contextos de promoção dessa lógica discursiva, como aqueles apontados anteriormente. Os dados aqui reunidos acionam falas públicas proferidas por esses artistas em eventos que compõem o que podemos identificar como um circuito de promoção do empreendedorismo local, sejam aqueles de caráter geral (como o Dia Mundial da Criatividade), sejam aqueles voltados especificamente para a discussão do mercado musical capixaba.

Nesse conjunto de dados, destacam-se os discursos atravessados pela ideia de protagonismo e empoderamento, sobretudo entre artistas mulheres, negros e/ou identificados como da periferia, bem como aqueles que acionam a identidade regional como elemento agregador, em função do estabelecimento de parcerias entre profissionais atuantes no mercado musical capixaba e com o seu público.

\footnotetext{
${ }^{8}$ Gentílico que se refere àquele que nasce no Estado do Espírito Santo, ao mesmo tempo categoria nativa que remete a uma identidade e cultura regionais.
} 
Finalmente, observamos como tais posicionamentos, ao mesmo tempo que alicerçados por uma lógica de valorização da iniciativa ("persistência" e, literalmente, "criatividade") individual, buscam se identificar com referenciais identitários capazes de potencializar a constituição de comunidades em rede como recurso à concretização desses projetos individuais (obtenção de sucesso na carreira) e coletivos (consolidação do mercado musical capixaba).

Por capixaba, categoria denominativa daquele que é natural da cidade de Vitória ou do Estado do Espírito Santo - ou que se apresenta como tal -, entende-se igualmente um determinado tipo de produto cultural. Esses atores estão inseridos em um contexto de valorização desse conteúdo, o que remete ao caráter autoral dos produtos apresentados, senão a consolidação de um mercado musical independente, capaz de superar as limitações contextuais de produção em que se encontra (fora dos principais polos do circuito nacional de produção musical e não vinculados às grandes gravadoras).

Nakano (2010) demonstra que, a partir da década de 50, a estrutura do mercado de produção musical se divide entre grandes empresas, majors, com grande poder econômico e que dominam a maior parte do mercado; e pequenas e médias empresas, ou indies, destacando ainda:

O acesso facilitado às tecnologias de produção permitiu o crescimento da cena independente, o surgimento da figura do artista-empreendedor, e mais ainda, permitiu que parte da produção musical fluísse de forma espontânea e descentralizada em nichos de mercado, criando públicos e artistas à margem do mainstream (NAKANO, 2010, p. 637).

No caso estudado, os nossos interlocutores acionam a categoria nativa independente para se referirem a uma forma de produção musical que, no limite, está desvinculada do grande mercado fonográfico, envolvendo recursos e suporte técnico pessoais ou colaborativos. Nesse sentido, o acesso às novas tecnologias digitais lhes permite produzir e divulgar seus trabalhos de forma autônoma. São, em muitos casos, "o músico que produziu seu CD num home studio", destacado por Vicente (2006, p. 17).

Produzir música capixaba independente não significa, segundo o observado em suas falas, se opor ao mercado fonográfico formal ou a sua lógica de organização, mas estar em uma condição de vulnerabilidade porque carente do suporte técnico e financeiro que o caracteriza, condição dotada de limitações e desafios específicos. E é em função da superação dessas limitações que eles se articulam em defesa da produção musical capixaba. 
Picchia (2013) irá sugerir, como categoria analítica, a sua classificação como artistas autônomos, dada a realização dos seus projetos exigir articulações com outros "independentes". O termo autônomo, deste modo, é proposto pelo autor para expressar a situação dessa nova geração de músicos que produz num mundo onde as grandes indústrias convivem como esse universo formado por uma classe de músicos autônomos. Optaremos pelo uso da categoria nativa reconhecendo, em consonância com o autor, que "O que une essa massa de novos músicos é acima de tudo um acesso facilitado a um conjunto de mediadores que antes eram monopólio de grandes conglomerados" (PICHIA, 2013, p. 178).

\section{Protagonismo em rede: mapeando os dispositivos de agenciamento entre membros da cena musical independente capixaba}

Considerando as transformações que ocorreram na indústria fonográfica mundial e, consequentemente, brasileira, Dias (2000) destaca aquelas relacionadas às fusões que ocorreram na indústria fonográfica entre as décadas de 70 e 90, levando, graças também ao processo de desenvolvimento tecnológico nesse período, a uma fragmentação da produção musical. Segundo a autora, essa fragmentação é consolidada nos anos 90, com a terceirização do trabalho e a desterritorialização da produção, fatores significativos na reorganização do desenvolvimento do capitalismo globalizado, referente à indústria fonográfica. A indústria fonográfica, que, até então, investia em casts estáveis, lucrando inclusive com a reedição de seus catálogos em $C D$ durante os anos 90, não se organizou devidamente para acompanhar o processo de reestruturação de novas formas de consumir música.

A partir do início do século XXI, a internet lança novas possibilidades para se produzir, divulgar e consumir música. Lima (2013) destaca que essa desterritorialização atingiu as grandes gravadoras, dado que a popularização do formato em MP3 juntamente com o acesso em banda larga permitiu a troca de arquivos via downloads de forma gratuita. A essa crise se soma o desenvolvimento de um mercado alimentado pela pirataria, e a reação das grandes gravadoras, em relação às plataformas que permitiam troca de downloads gratuitos, foi atuar no campo jurídico ${ }^{9}$ (MIDANI, 2008).

\footnotetext{
${ }^{9}$ A troca de downloads gratuitos foi considerada crime contra os direitos autorais das gravadoras e dos artistas e objeto de disputa pelo pagamento de direitos autorais, multas, entre outros.
} 
Essas transformações provocaram o acirramento das assimetrias e conflitos de interesses envolvendo gravadoras, músicos, produtores e órgãos reguladores. Apesar das resistências, novos desafios, em detrimento de antigas fórmulas, estavam lançados pelas tecnologias, que fizeram com que o mercado fonográfico e seus agentes precisassem se adaptar para se manterem ativos. A superação da crise, inevitavelmente, exigia o entendimento da dinâmica do ciberespaço (outros ambientes de sociabilidade não presencial) e a utilização de novas estratégias de negócio que pudessem assimilá-lo. Segundo Castro (2004), uma das primeiras estratégias adotadas pelas majors/gravadoras, como resposta ao potencial do mercado mundial on-line, foi disponibilizar downloads de baixo custo através da regulamentação e distribuição via internet, garantindo o pagamento de royalties por cada faixa disponibilizada.

Em um mercado mundial globalizado, esses autores destacam que as relações estabelecidas entre gravadoras, produtores, artistas/músicos, associações de artistas/músicos, órgãos reguladores, plataformas de downloads gratuitos, plataformas de streaming e empresas de tecnologia passaram por diversas alterações. Relações marcadas pela assimetria, complexidade e conflito. Porém, essas foram racionalmente reinventadas pela lógica do capitalismo financeiro, entendido aqui como um capital especulativo e dirigido por grupos de acionistas, que, através de novos modelos de negócios, mantiveram a velha estrutura de acúmulo capitalista: uma lógica de poder agora dissimulada pelas ditas opções de livre consumo para o público consumidor e de livre espaço de criação para os artistas e músicos (RODRIGUES, 2019).

$\mathrm{Na}$ atualidade, a dinâmica de consumo musical está intimamente ligada às plataformas de streaming ${ }^{10}$, a internet tornando-se um espaço de divulgação e visibilidade para os músicos e suas produções bem como de promoção dos circuitos locais.

Por se tratar de um fenômeno social dinâmico e fluido, o atual cenário musical, autoral e independente, em Vitória, demonstrou apresentar uma lógica articulada entre o consumo de música virtual e as apresentações ao vivo. Ele se efetiva em um circuito (MAGNANI, 2010) que envolve casa de shows, pubs, pequenos festivais, sites, blogs, programa de rádio, eventos de formação musical e uma série de iniciativas e parcerias dos artistas para a capitação de recursos e divulgação para fomentar a visibilidade dos trabalhos dos artistas locais, além

10 "Receita com streaming de música supera vendas físicas pela primeira vez, diz indústria fonográfica", Estadão, 24-04-2018. Acesso em: 09 maio 2018. 
das redes sociais e as plataformas de streaming $^{11,}$, como demonstra Rodrigues (2019).

A circulação por esses espaços de sociabilidade que compõem o circuito local de promoção da música capixaba independente para os músicos, os produtores, bem como para seus públicos, caracteriza, mesmo que em diferentes dimensões, a dinâmica de consumo da música autoral em Vitória. É através de uma dinâmica de exposição pública dos artistas, não apenas como parte da agenda desses eventos, mas também como seu público de frequentadores, que se constrói a sua relação com os consumidores dos seus produtos em potencial. Interagir intensamente com esse público-alvo é parte fundamental do processo de construção de suas carreiras.

Esses espaços de sociabilidade foram mapeados e observados ao longo do trabalho de campo de Rodrigues (2019). Ao mesmo tempo, atividades de outra ordem, como debates públicos em torno dos desafios da produção musical local, nos levaram ao circuito de promoção do empreendedorismo local como espaço de observação, dada a presença recorrente de atividades envolvendo artistas locais identificados como integrantes da dinâmica de produção musical independente capixaba ${ }^{12}$. Nessas ocasiões, especificamente, mas não exclusivamente, nos chamou atenção a aproximação dos posicionamentos dos profissionais do mercado da música presentes com relação àqueles dos empreendedores culturais atuantes no Centro da cidade, de um modo mais amplo $^{13}$.

Se, por um lado, a ascensão de uma lógica discursiva marcada pelas novas modalidades de justificação do sistema capitalista fora especificamente acompanhada entre os segundos; por outro lado, ela estava igualmente presente nas falas dos primeiros, por mais que esses conjuntos de atores se diferenciem pelo seu perfil de atuação.

11 Algumas dessas iniciativas relacionadas ao fomento e captação de recursos são viabilizadas através da participação do poder público local via editais promovidos pela Secretaria de Estado da Cultura (Secult/ES).

12 Categoria nativa acima explicitada.

${ }^{13}$ Os dados aqui acionados foram coletados por pesquisadores do Núcleo 29: grupo capixaba de estudos da experiência humana em meio urbano, ao longo da realização das suas pesquisas individuais ou em empreitadas coletivas sob orientação da profa. Dra. Manuela Vieira Blanc. Debruçados sobre diferentes contextos de coleta de dados e com o uso dos métodos de observação participante e da realização de entrevistas semiestruturadas, e ao mesmo tempo articulados em questões transversais ao desenvolvimento desses diferentes trabalhos, os esforços coletivos dos pesquisadores do grupo nos permitiram cobrir diferentes eventos, movimentos e expressões que compõem o que aqui denominamos circuito de promoção do empreendedorismo capixaba, (caso de NÉSPOLI, 2016; MOREIRA, 2018; RODRIGUES, 2019). 
O grupo de interlocutores entrevistado por Néspoli (2016) e categorizado então como empreendedores culturais se caracteriza por um conjunto de atores engajados em projetos que têm por pretensão promover a dinamização cultural do Centro da capital (sua revitalização, requalificação ou reavivamento, categorias acionadas em diferentes momentos por esse mesmo conjunto de pessoas), mas com perfis diferenciados de atuação. Eram, grosso modo, comerciantes que promoviam, direta ou indiretamente, eventos culturais que compunham uma agenda de ofertas desses serviços no bairro. Pessoas de algum modo envolvidas com a dinamização da região, algumas também atuantes como artistas (atrizes, estilistas, músicos, entre outros), bem como donos de estabelecimentos identificados como pontos de interesse nesse mapa, com certo grau de influência e visibilidade (como donos dos botecos onde acontecem rodas de samba tradicionais e frequentados por um público mais amplo também, porque frequentados por conhecidos sambistas locais, entre outros casos específicos). Algumas dessas personagens estabeleciam uma relação personalista com o seu público, outras, não. De um modo geral, não produziam o produto cultural que comercializavam (ou não exclusivamente): não foram selecionados por serem artistas, mas pela sua atuação na cena cultural do bairro.

Diferentemente, as personagens da cena musical capixaba independente, a cujas falas nos referiremos especificamente neste artigo, os artistas são eles próprios os produtos que promovem, não apenas dada a dinâmica que caracteriza o circuito musical local, mas também dada a sua atuação como músicos autorais. E essa diferença de posição irá incidir sobre seus posicionamentos críticos com relação ao seu contexto de atuação, bem como envolver estratégias específicas de agenciamento.

Ao mesmo tempo que buscam conformar comunidades em rede capazes de potencializar a promoção da sua produção, se confrontam nas disputas pela definição de sua identidade comercial. Deste modo, engajados a posicionamentos passíveis de serem enquadrados em uma lógica identitária fragmentada, articulam estruturas discursivas e narrativas ligadas a sistemas de representação e que colocam em questão relações de poder (SILVA, 2005).

Analisando o atual circuito local e independente de produção musical na cidade de Vitória/ES, é possível verificarmos assimetrias em seu processo de produção, denunciadas por grupos que se posicionam a partir de recortes de gênero, de raça e de posição social no interior desse campo. Nossos diferentes interlocutores acionam um ou vários desses dispositivos ao longo das suas falas, ao analisar sua própria trajetória ou o contexto de produção local. Outro 
elemento que atravessa esses posicionamentos, de modo mais secundário nas falas dos artistas nos contextos observados, porém recorrente e relevante para pensar a cena musical capixaba de um modo mais amplo, é a identidade regional.

O Bate-papo realizado no dia 21 de abril de 2018 como parte da programação do Dia Mundial da Criatividade ocorreu no restaurante Grappino $^{14}$, e tinha como proposta temática Ascensão da mulher na cena musical capixaba como forma de expressão. As cantoras Gabriela Brown (em carreira solo), Aressa Alves (da Banda Alquimistas), Victória Dessaune (do Fita Demo) e Morena (do grupo Solveris) compuseram a mesa, e as duas primeiras coordenaram a roda de conversa, envolvendo o público presente.

As palestrantes conduziram suas falas denunciando as desigualdades de gênero na produção musical local, a recorrência do assédio sexual envolvendo artistas e seus produtores, e destacando o protagonismo feminino na cena musical capixaba, entendido por elas como esforço de resistência (diante dos constrangimentos experimentados) e prova da sua centralidade para a dinamização do mercado local.

Gabriela Brown deu muita ênfase em sua fala quando se referiu à relação assimétrica entre músico e produtor em dois aspectos. O primeiro trata-se da interferência do produtor no processo de criação, durante o qual se coloca como patrono da obra, na medida em que se posiciona como mediador no processo de criação, divulgação (local de gravação, lugares para o artista se apresentar) e patrocínio (recursos) da carreira artística.

Willians (1992) destaca como, nas relações de produção e consumo inseridos na indústria cultural, toda obra de arte possui o seu patrono além do seu autor, o primeiro ocupando um lugar de extrema importância como patrocinador, produtor e divulgador da obra. Esse patrono geralmente é uma instituição legitimada dentro de determinado campo artístico e que detém o capital econômico e social, ocupando, portanto, uma posição de poder. A própria relação entre patronos e artistas, desse modo, gera tensões e assimetrias conforme a dinâmica de interesses a partir da qual o mercado estabelece como produto cultural. No caso observado, a artista (não contando com uma vinculação contratual propriamente dita) denuncia os efeitos dessa relação no seu processo produtivo e em sua trajetória de carreira, ainda em caráter independente. Não se trata de uma relação estável de cooperação, dotada de

\footnotetext{
${ }^{14}$ Bar localizado no Centro da cidade e cuja centralidade no circuito de promoção cultural local tornou seu dono um dos interlocutores de pesquisa de Néspoli (2016), então selecionado como empreendedor cultural atuante na região.
} 
contrapartidas e benefícios agregados, mas, ainda assim, esta está marcada por aspectos semelhantes àqueles de um artista que o possui.

O segundo aspecto levantado pela artista como sintomático às relações de poder às quais as artistas mulheres estão sujeitas diz respeito ao recorrente assédio dos produtores. Ao se identificar como lésbica, Gabriela demostrou extremo incômodo com o que expressa como o simples fato de ter mais atenção (em comparação com músicos homens) e muita interferência por parte de produtores homens em seu trabalho. Relatando situações de assédio e interferências em suas obras, a artista destacou que a posição de poder ocupada pelos homens no mercado musical é um empecilho para a liberdade artística das mulheres. Diante de tal incômodo, relata já ter recusado alguns trabalhos devido ao seu desconforto diante de comportamento abusivo ou assediador.

Já no contexto do evento Formemus, a primeira mesa temática, composta igualmente por mulheres, tratou de discutir a produção musical e o protagonismo da música na periferia. Sob a alcunha protagonismo, aqui analisada como categoria nativa, nossos interlocutores referem-se a iniciativas independentes dos músicos e produtores culturais, práticas de resistência (em seus termos) com relação ao mercado formal, dominado pelos grandes investidores do setor. Protagonizar, nesse sentido, ou resistir, é assumir para si a responsabilidade por produzir as condições do próprio sucesso, assim como o demonstrado acima.

Nakano (2006) demonstra que, apesar de, desde o seu advento, se colocar como espaço de resistência cultural e política à nova organização da indústria, a produção independente surge como uma estratégia possível para viabilizar o desenvolvimento da carreira do artista que, a princípio, não implica necessariamente um questionamento da indústria musical. Nesse sentido, podemos observar como a valorização dessas estratégias de produção, que remetem a um posicionamento crítico e politizado, nada mais é do que uma prática de justificação que visa efetivar uma condição contingencial. Ao contrário, Vicente (2006, p. 6) destaca como a cena independente assume "também o papel de prospectar novos nichos de mercado e formar artistas para as grandes gravadoras, respondendo com maior precisão à crescente segmentação do público".

Em sua fala, no Dia Mundial da Criatividade, Morena destaca com orgulho que o seu primeiro EP custou $\mathrm{R} \$ 300,00$ e foi produzido em seis horas no Guanaaní Hostel (Centro de Vitória/ES). Ela mesma pintou as roupas que utilizou para a gravação do clipe, juntando recursos com amigos e familiares, considerando a sua atitude empreendedora como algo ousado, diante das 
condições dadas no momento. Os dados de Picchia (2013) corroboram com esses indicativos na análise da produção fonográfica entre músicos autônomos em São Paulo. O autor conclui que "a produção fonográfica desses jovens artistas se caracteriza por um curto-circuito entre arte e técnica" (p. 174), ao mesmo tempo que as hierarquias verticais sendo suplantadas pelo cooperativismo horizontal.

Uma das principais estratégias actanciais identificadas em nosso espaço de observação é o posicionamento identitário. Entre nossos interlocutores, demarcar posições é traduzir afinidades, pertencimentos e interesses pessoais em interesses comuns, alimentando comunidades em rede através da atração de um público consumidor em potencial.

Debatendo a relação entre a produção e o mercado, as questões levantadas no Formemus giram em torno dos limites entre a construção da carreira, em termos de vendabilidade, e a sua gestão, no que se refere à imagem transmitida pelo artista. Mais uma vez, a crítica às condições de produção musical em Vitória e no Estado do Espírito Santo não se direcionam à dinâmica do próprio mercado, sendo pensadas como aspecto concernente ao artista, sua identidade e seu posicionamento. A sua subordinação a essa lógica é, finalmente, naturalizada.

O ser mulher, nas falas dessas artistas, é um elemento acionado na disputa por uma posição no interior da cena musical local, denunciando as assimetrias no interior desse contexto e destacando a condição de gênero como um dispositivo de poder que torna suas condições de trabalho ainda mais precárias. Ao mesmo tempo que relatam situações de assédio, disputam pela efetivação do seu protagonismo, seja na dinamização do mercado musical local, seja enquanto prática de resistência com relação às desigualdades de gênero experimentadas.

Aressa destaca em sua fala algumas situações nas quais homens mexem nos equipamentos sem a permissão da banda, bem como xingamentos em situação de conflito nas quais a opinião das mulheres é desqualificada, entre outras situações que classifica como inconveniências durante os shows.

As palestrantes em ambos os eventos entram em consonância quando a temática é a desigualdade de gênero no contexto capixaba de produção musical. Todas concordam entre si quanto à deslegitimação e objetificação por parte dos homens em situações cotidianas que dizem respeito ao exercício do seu trabalho. Gabriela destaca tais distinções no tratamento em relação à mulher dependendo do gênero musical, citando a diferença entre o jazz e o soul, por exemplo. Aressa relaciona a ascensão na cena musical capixaba como 
emergência de práticas de resistência femininas, incidindo sobre o material artístico que atravessa o conteúdo das suas composições.

Nesse momento, uma mulher jovem e negra, presente na plateia, reforça o debate em torno do lugar de fala, ressaltando que enquanto mulher se sente mais segura quando frequenta um show (citando os da Gabriela como exemplo) em que a maioria do público é composta por mulheres e, principalmente, mulheres lésbicas.

Por um lado, essas falas acionam a composição de uma comunidade em rede que interpela as mulheres presentes a apoiar o trabalho das artistas mulheres locais, refletindo diretamente uma competência básica ao ator por projeto de Boltanski e Chiapello (2009). Ser mulher no mercado da música capixaba é articular um pertencimento que também potencializa conexões. Deste modo, denunciar a desigualdade de gênero que atravessa as relações no interior do mercado de música autoral local é também buscar articulações que contribuam para uma melhor inserção como artista local. $\mathrm{O}$ engajamento a um posicionamento demarcado em termos de gênero e, alguns casos, etnia, interpela o público potencial dessas artistas a fortalecê-las, pela valorização do seu trabalho, mas também em função do fortalecimento da comunidade imaginária da qual fazem parte ao partilhar dadas características e uma posição no mundo.

Por outro, essas artistas conferem destaque para as estratégias empreendidas em função da prospecção das suas carreiras e que dizem respeito às competências dos atores por projeto, também pensados pelos autores supracitados.

Arissa anuncia, ao final da sua fala, e com entusiasmo, que o baixista da banda da Pitty, artista de expressão nacional, estava produzindo um $E P^{15} \mathrm{com}$ a banda que ela compõe, parceria prevista para acontecer no mês seguinte à sua fala. Ao se referir às suas estratégias de marketing, Morena categoriza a capitalização de recursos entre apoiadores como resistência, já que assim tem mais liberdade para produzir aquilo com o que se identifica.

A capacidade de se fazer por si mesmo, esperada desse empreendedor de si (FOUCALT, 2008), adaptado ao contexto neoliberal, envolve, em Boltanski e Chiapello (2009), a capacidade de dar conta das articulações necessárias para

\footnotetext{
${ }^{15}$ Extended play $(E P)$ é uma gravação em disco de vinil ou $C D$ que é longa demais para ser considerado um single e muito curta para ser classificada como álbum musical. Atualmente o EP ou EPs tem sido muito utilizado para lançamentos em plataformas de streaming como estratégia de divulgação, distribuição e monetização que pode ser considerada mais econômica em termos de investimento para o artista independente.
} 
fazer acontecer seus projetos. Assim essas artistas constroem e consolidam a sua relação com seu público, colocando-se como representantes e porta-vozes de um discurso de valorização identitária, como podemos observar no trecho da música "Bonito é o quê?" de Gabriela Brown:

\section{Me ensinaram que era feio ela e o corpo dela \\ Feio ser a chave pra abrir a própria cela \\ Feio ser pincel pintar a própria tela}

Observa-se como a imposição de um padrão estético feminino é questionado, bem como defendido um agenciamento ativo e questionador do que podemos supor ser um posicionamento submisso e recatado, em seus termos. Protagonismo feminino aqui diz respeito à construção de uma autonomia, empoderamento refere-se ao reconhecimento do próprio valor. Em "Anti Maré", essa condição feminina é novamente colocada quando, à frente ao verso "Dificil é existir em um planeta que nem esse nosso", a compositora destaca: "Sou mulher, carrego a alma armada" (Gabriela Brown).

Desse modo e no contexto de produção musical em que se encontram, essas artistas deslocam sua crítica do mercado fonográfico ao seu espaço e cotidiano de atuação, adaptando-se à situação em favor da realização dos seus projetos.

Aressa explica que encontrou algumas dificuldades em captar recursos que vão desde o problema em conseguir equipamentos, uma vez que a maioria dos meios necessários para produção bem como todo o seu processo está majoritariamente sob posse de profissionais homens. Nesse ponto, ela destaca a importância da ascensão da mulher na atual cena musical num ambiente historicamente dominado por homens.

Resistir como mulher no cenário musical capixaba é protagonizar uma luta pessoal, empreender como atriz individual que busca em seus pares e público condições para fazer possível e o motor de realização dos seus projetos. Articular uma comunidade em rede composta por esse público de produtoras e consumidoras é a estratégia que defendem na consolidação de um espaço de atuação.

Entre as artistas negras, esse posicionamento se complexifica, articulando as questões de gênero às questões raciais, como na definição de um "afrofeminismo", na letra de "Se liga, meu bem", da banda Alquimistas, letra composta por Cibele Verrangia e Cinthia Caetano. A música se inicia com o trecho: 
Ação de Dandaras, Jovelinas, Zacimbas, Marias Padilhas

Empoderada na luta, na dor, no afeto e no papo reto

Carrego na alma, as marcas da chibata

E na dança, no canto, no som do tambor, sintetizo o meu manifesto ]

De lutar, extravasar, transformar, amar, vibrar, AFRONTAR

Articulando personagens simbólicas de uma cultura feminina negra e de resistência, a música coloca em questão a imposição de um padrão estético feminino branco, convida para um posicionamento político engajado e para a composição de forças, como no trecho "E de mãos dadas, almas enlaçadas, revolucionar nossa área há tanto tempo subjugada" (Cibele Verrangia e Cinthia Caetano).

Aressa Alves, que faz parte da banda, composta somente por mulheres, fez questão de destacar em sua fala durante o bate-papo que a estética musical do grupo busca um posicionamento afirmativo, posicionado com relação às questões que envolvem a objetificação do corpo e dos afetos femininos.

Não apenas o ser mulher, mas o ser mulher negra, no contexto local, é o lugar de fala do qual partem essas artistas. $O$ que observamos nesse cruzamento de fragmentos identitários é a composição de camadas de elementos em disputa, que igualmente servem ao posicionamento dessas artistas, incidindo sobre as assimetrias que denunciam no interior da cena musical capixaba, bem como sobre a construção das suas trajetórias profissionais. Esse empreendimento é politicamente engajado e assim se compõe em torno de um público dotado de problemas específicos.

A questão racial é um elemento que atravessa as composições de artistas negros capixabas de um modo amplo, bem como a que diz respeito às desigualdades sociais. Não apenas atravessa suas produções, como está presente em suas falas. Desse modo, esses diferentes atores disputam seu espaço no cenário local denunciando desigualdades de condições específicas, relacionadas aos seus engajamentos identitários.

Morena destacou, em sua fala do dia 21 de abril de 2018, a necessidade de segmentar um público através da proposta artística e fazer música de alguma necessidade afirmativa. Assim, ela não apenas argumentou sobre a necessidade de consolidação de um público local de jovens, como também destacou acerca da importância que as plataformas de streaming possuem na solidificação desse público, pois colaboram para dar visibilidade ao trabalho. Esse público, segundo sua fala, expressa a identificação não apenas com o produto, mas com a aquilo que ele representa. Não um produto genérico ou mesmo neutro, mas engajado às causas levantadas pelos seus produtores. Sendo parte de um grupo 
de rap composto por outros três homens, Morena destacou as dificuldades especificamente vivenciadas por artistas que trabalham com um gênero musical majoritariamente masculino.

Ao mesmo tempo, a produção musical capixaba independente é marcada, em termos mais amplos e gerais, pela valorização da identidade regional como dispositivo que visa à articulação dos próprios artistas locais bem como dos seus públicos. Novamente, as desigualdades na condição de produção, experimentadas por esses artistas que não contam com a vinculação a uma grande gravadora, ou com uma prospecção de carreira mais ampla e estável, são enfrentadas com estratégias que partem da mobilização de esforços entre seus pares.

Na prática, não são as condições de mercado que são colocadas em questão, mas as identidades em disputa. Ao mesmo tempo que, individualmente, competem por espaço através de um discurso de valorização da sua capacidade individual de agir, sob a égide do protagonismo (seja ele feminino, negro, ou periférico), e que se confrontam mutuamente na busca pela consolidação das suas comunidades em rede, articuladas a identidades fragmentadas, defendem a composição de parcerias entre pares como ferramenta de consolidação do mercado musical local em função de sua prospecção à nível nacional.

Ao expressarem criticamente as suas diferenças, esses atores enquadram suas preocupações de acordo com qualificações rivais de bem comum (de objetivo a ser perseguido ou problema a ser combatido) (THÉVENOT, 2019). Ao mesmo tempo que essa gramática de engajamento exige a transformação das preocupações pessoais, que devem ser ampliadas para se qualificarem enquanto bem compartilhado, é limitada enquanto catalisadora de uma pluralidade de bens fundamentais (BREVIGLIERI, 2013), reduzindo a abrangência da crítica aos aspectos particulares das experiências compartilhadas.

O reconhecimento da precariedade das condições de produção que enfrentam fundamentam esse discurso de efetivação dos seus papéis no circuito musical capixaba. Essa crítica diz respeito, na prática, ao não reconhecimento do valor desse produto local, não ao modo como esses critérios de valor são estabelecidos. O caminho para esse reconhecimento, portanto, é o fortalecimento das suas bases de criação, em âmbito local, perpassando o engajamento individual dos artistas como empreendedores individualmente comprometidos com esse projeto coletivo, o que é a base da crítica aos artistas capixabas que conseguiram se consolidar no mercado nacional e que, nesse processo, se distanciam dos demais artistas locais. 
Ainda no bate-papo ocorrido no Dia Mundial da Criatividade, Humberto, integrante e baixista do grupo "Severino" e do "Assédio coletivo", discorre sobre a desunião no meio musical local. Cita exemplos de gente que conseguiu se destacar no meio artístico e depois não levou em consideração a situação local. Ele citou exemplos de festivais dos quais participou ao longo de sua carreira, em que aconteceram situações de ser ignorado por músicos locais que já tinham um público fora do Estado.

A fala de Humberto destacou de forma saudosista, otimista e regionalista a cena do congopop, liderada pelos grupos Casaca e Manimal, no final dos anos 1990 e começo dos anos 2000 (BRAVIN, 2008), quando o cenário musical local "quase chegou lá". Ele realçou a cena musical natalense (O festival do sol, por exemplo) como uma boa referência de união entre os músicos, criticando a cena do rock por ser sectária e enfatizando a importância da difusão no circuito para além de uma dimensão local.

Na mesma ocasião, Gabriela enfatizou a importância da colaboração entre músicos na sua carreira, através de indicações.

Essas conexões temporárias, ou parcerias profissionais, mencionadas por nossos interlocutores não apresentam vínculo de estabilidade, são dadas em função dos projetos em andamento e enquanto estes se desenvolvem. Essas parcerias constituem-se como um amontoado de conexões ativas capazes de potencializar objetos e sujeitos, mas que, por serem temporárias e mesmo frágeis, demonstram sua vulnerabilidade. Analisando a cena musical independente em Vitória/ES através desses relatos, observamos que, sob a lógica do empreendedorismo, tais atores sociais estabelecem relações entre si cuja ideia de valor agregado ao produto (neste caso a música como produto cultural) é fundamentada pela exigência de ampliação de redes e conexões estabelecidas. Se a identidade regional não é capaz de dar conta desse empreendimento, fortalecendo os artistas locais como parte de uma mesma comunidade em rede e contribuindo para a sua prospecção, as identidades fragmentadas servem como recurso à consolidação de públicos restritos a nichos de mercado locais. Desse modo, empreender é fazer acontecer pelo próprio esforço, protagonizar é resistir no interior de um sistema desigual, carente de recursos e limitado em seu potencial de abrangência de mercado. 


\section{Considerações finais}

Empreendedorismo, criatividade e inovação são noções especialmente destacadas e debatidas ao longo dos últimos anos entre os empreendedores culturais da cidade de Vitória/ES. Observamos ao longo dos últimos anos a consolidação de um circuito de promoção do empreendedorismo local, estimulando em seus participantes o engajamento em um papel de empreendedor de si (FOUCAULT, 2008), característico ao posicionamento do ator por projetos (BOLTANSKI; CHIAPELLO, 2009).

Para Boltanski e Chiapello (2009), diferentemente do segundo espírito do capitalismo, período durante o qual as empresas ainda disponibilizavam um plano de carreira, bem como aos profissionais era exigida alta especialização em determinado setor de atividade, o novo espírito do capitalismo coloca a própria ideia de trabalho em questão, exigindo do trabalhador a competência de autogerir a sua atividade e adaptar-se às diferentes demandas do mercado. A possibilidade de construção de uma carreira, colocada em risco dada a flexibilização das relações de trabalho no interior de um capitalismo neoliberal, é substituída pela defesa de uma maior autonomia para o profissional, agora carente de garantias trabalhistas, microempreendedor individual.

Dada a reconfiguração da indústria cultural a partir do desenvolvimento das novas tecnologias e plataformas de consumo musical, essas transformações incidem sobre as assimetrias de condição de produção. Na atualidade, essas relações de poder se assentam ainda em condições de produção flexibilizadas e em uma condição de ainda maior vulnerabilidade para os artistas (WILLIAMS, 1992).

Esse processo de fragilização das condições de trabalho é sustentado por um discurso que toma a autonomização do trabalhador como um fenômeno positivo, um novo espírito de engajamento ao sistema capitalista, igualmente marcado pela negação das suas contradições. Ao mesmo tempo que ele não tem garantias ou estabilidade, deve estar aberto a se engajar não em um trabalho, mas em projetos, a constituição de redes de relações profissionais (ou network) sendo basilar ao sucesso, dado permitir o estabelecimento de parcerias e melhores condições de inserção no mercado (BOLTANSKI; CHIAPELLO, 2009).

Entre os músicos atuantes na cena capixaba independente, esse discurso perpassa a valorização da capacidade de cooperação, resistência (ou protagonismo) e empreendedorismo, bem como a valorização dessa suposta maior autonomia para produzir e se relacionar com o público consumidor, 
dadas pelas plataformas digitais (em conformidade com o apontado por VICENTE, 2006).

Diante da tal perspectiva, ou da ausência de alguma, cada projeto proporciona a ideia de que os trabalhadores (agora empreendedores) terão a oportunidade de conhecer novas pessoas, adquirir novas competências inovadoras, podendo passar de um negócio/contrato para outro, conforme o seu desempenho (BOLTANSKI; CHIAPELLO, 2009).

Assim, entre nossos interlocutores, a ausência de estabilidade contratual, ao invés de alvo de crítica, é positivada como ampliação da autonomia autoral, e as assimetrias percebidas são relacionadas às condições particulares de inserção no mercado (gênero, etnia ou nicho de atuação) e não à conformação da própria indústria cultural. Ao mesmo tempo, "as novas tecnologias fornecem condições para um novo tipo de produção fonográfica e um novo tipo de divulgação que produzem um novo tipo de artista" (PICCHIA, 2013, p. 173), atuando como aliados que amplificam e espalham a agência desses sujeitos musicais e seus produtos.

Este artigo se propôs a analisar, a partir de um recorte, alguns dos dados obtidos ao longo de um trabalho de campo que vem sendo realizado no âmbito do Grupo de Pesquisa Cidades, Espaços Públicos e Periferias e que subsidiaram o desenvolvimento da dissertação de mestrado "Segue o som! Uma etnografia da música autoral em Vitória/ES", ${ }^{16}$. Analisando a cena musical capixaba, os modos como os artistas atuantes na cidade de Vitória, Estado do Espírito Santo, se articulam entre si, bem como aquilo que dizem sobre o que fazem (GEERTZ, 2008) no que se refere à gestão das suas carreiras, optamos por selecionar as falas públicas de alguns desses artistas durante eventos realizados no interior de uma agenda de atividades que aqui denominamos circuito de promoção do empreendedorismo local.

Contextualmente, a ascensão que atribui aos atores individuais a responsabilidade pelo seu sucesso ou fracasso, no campo da produção musical local, foi uma tendência observada nos mais diferentes contextos de observação e relatos analisados. Enquanto, em termos gerais, os artistas capixabas cujo posicionamento fora analisado acionam a identidade e pertencimento regionais como elemento articulador de comunidades em rede, buscando motivar parcerias entre seus pares, bem como atrair o seu público consumidor direto, as mulheres acionam seu lugar de fala, marcado pela desigualdade de gênero

16 Orientada ao longo dos seus primeiros 20 meses por Manuela Vieira Blanc e finalizada sob a orientação do professor Pablo Ornelas Rosa no Programa de Pós-Graduação em Sociologia Política, Universidade Vila Velha, ES. 
exemplificada em situações de trabalho, como elemento definidor da posição que ocupam no campo da produção musical local. E assim, sucessivamente, entre artistas negros (mulheres e homens) e periféricos (sejam moradores de bairros pobres e estigmatizados e/ou produtores de nichos de mercado assim percebidos por eles mesmos, sobretudo, no que se refere aos ritmos nos quais atuam).

Analisando o discurso desses artistas, observa-se que a valorização de um engajamento individual no projeto de construção das suas carreiras bem como a exaltação de suas identidades fragmentadas como lógica justificatória às parcerias estabelecidas (no âmbito da produção bem como do consumo) se insere em um processo de mercantilização do autêntico, um fenômeno contemporâneo apontado por Boltanski e Chiapello (2009) como característico ao que definem como novo espírito do capitalismo.

Para os autores, a mercantilização do autêntico supõe que a singularidade dos bens comerciais, ou seja, a experiência gerada por meio de trocas simbólicas, serve como referência ao "valor de uso" agregado ao bem comercial. Segundo os autores, a mercantilização do autêntico ligada ao regime do capital e, consequentemente, da circulação comercial, opera o material e imaterial (real ou virtual) enquanto objeto de desejo, potencialmente como fontes de lucro. Tais processos destacados pelos autores como a "transformação do não capital em capital" servem como fio condutor para uma série de operações de produção (neste caso, através da música), conforme destacam os autores na relação entre produto, empreendedorismo de si e empresário de si

Desenvolvida inicialmente no campo (economicamente marginal durante
muito tempo) das empresas culturais - edição, produção de discos,
orquestras, galerias de arte - nas quais o desempenho econômico se baseia
fundamentalmente na capacidade do empreendedor de pressentir, na
relação pessoal, as possibilidades de um criador e de se antecipar aos
gostos e desejos de um público, essa lógica ganhou dimensões
consideráveis, durante os últimos trinta anos, com a importância
crescente dos investimentos culturais e tecnológicos e com o
desenvolvimento dos serviços, especialmente do turismo, da hotelaria,
dos restaurantes, da moda, do prêt-à-porter, da decoração de interiores e
do designo É a lógica dos "managers", cujas competências são,
simultaneamente, competências de artista, organizador e homem de
negócios (BOLTANSKI; CHIAPELLO, 2009, p. 446).

Deste modo, articulando elementos das suas identidades fragmentadas (SILVA, 2005), esses atores acionam modalidades de agir em conjunto em 
conformidade com suas estratégias de sobrevivência na cena musical independente capixaba, o que aponta para o seu potencial de agir conforme a situação, negociando estratégias criativas favoráveis à sua prospecção na cena local.

\section{Referências}

BOLTANSKI, Luc; CHIAPELLO, Ève.

(2009). O novo espírito do capitalismo. São Paulo/SP, Ed. Martins Fontes.

BRAVIN, Adriana.

(2008). Congopop: Mídia, música e identidade capixaba. Vitória/ES, Ed. do Autor.

BREVIGLIERI, Marc.

(2013). Une brèche critique dans la ville garantie? Espaces intercalaires et architectures d'usage. In : LANZA, E. Cogato; PATTARONI, L.; PIRAUD, M.; TIRONE, B. De la différence urbaine. Le quartier des Grottes / Genève.. G. Genève: Mettis Presses.

DIAS, Marcia Tosta.

(2000). Os donos da voz: indústria fonográfica brasileira e mundialização da cultura. São Paulo: Boitempo.

FOUCAULT, Michel.

(2008). Nascimento da biopolítica. São Paulo: Ed. Martins Fontes.

GEERTZ, Clifford.

(2008). A interpretação das culturas. Rio de Janeiro: LTC.

HOBSBAWM, Eric.

(1990). História social do jazz. Rio de Janeiro/RJ, Ed. Paz e Terra.

IFES.

(2013). Ministério da Educação. Shell Brasil oferece Programa de Empreendedorismo. Disponível em: https://ifes.edu.br/noticias/14143-shellbrasil-oferece-programa-deempreendedorismo, Acesso em: julho de 2017.
LIMA, Tatiana Rodrigues.

(2013). O balanço do bit: mediação da música na era digital. Tese de Doutorado (Comunicação e Cultura Contemporâneas). Universidade Federal da Bahia.

MAGNANI, José Guilherme Cantor.

(2010). Os circuitos dos jovens urbanos. Sociologia: Revista do Departamento de Sociologia da FLUP, vol. XX, p. 13-38.

MIDANI, André.

(2008). Música, ídolos e poder. do vinil ao download. Rio de Janeiro: Nova Fronteira.

RAMOS, Liliane Moreira.

(2008). O consumo político e a crítica no discurso de um grupo de empreendedores sustentáveis da Grande Vitória/ES. Dissertação (Mestrado em Sociologia Política) - Universidade Vila Velha, Vila Velha.

NAKANO, Davi.

(2010). A produção independente e a desverticalização da cadeia produtiva da música. Revista Gestão e Produção, São Carlos.

NÉSPOLI, A. A.

(2016). Qual é o rock hoje?: empreendedorismo cultural no centro de Vitória-ES. 138. Orientadora: Manuela Vieira Blanc. Dissertação (Mestrado em Sociologia Política) - Universidade Vila Velha, Vila Velha. Disponivel em: https://repositorio.uvv.br/bitstream/12345 $6789 / 167 / 1 /$ DISSERTA $\%$ c3\%87\%c3\%830\%2 OFINAL20DE\%20AMANDA\%20ALVARENGA\%2 ONESPOLI.pdf. Acesso em: 28 jun. 2018. 
PICCHIA, Paulo Menotti del.

(2013). Por que eles ainda gravam? Discos e artistas em ação. Dissertação (Antropologia Social). Universidade de São Paulo.

PRESTIFLIPP0, Agustín Lucas; WEGELIN, Lucía. (2016). El neoliberalismo como trama ideológica en la Argentina reciente. Utopía y Praxis Latinoamericana, vol. 21, n. 74, julioseptiembre.

RODRIGUES, Fabio.

(2019). Segue o som! Uma etnografia do circuito da música autoral de Vitória/ES. Dissertação (Mestrado em Sociologia Política) - Universidade Vila Velha. Vila Velha - ES, p. 155.

SILVA, Tomaz Tadeu da.

(2005). A produção social da identidade e da diferença. Identidade e Diferença: a perspectiva dos Estudos Culturais. Petrópolis: Editora Vozes.

THÉVENOT, Laurent.

(2019). How does politics take closeness into acount? International Journal of Politics, Culture, and Society.

VICENTE, Eduardo.

(2006). A vez dos independentes(?): um olhar sobre a produção musical independente do país. COMPOS: Revista da Associação Nacional dos Programas de Pós-Graduação em Comunicação.
WERNECK, Alexandre.

(2012). A desculpa: A circunstância e a moral das relações sociais. Rio de Janeiro: Civilização Brasileira.

WILLIAMS, Raymond.

(1992). Cultura. Rio de Janeiro, Ed. Paz e Terra.

Quanto às contribuições individuais de cada um dos autores, os dados acionados neste trabalho foram coletados no âmbito do Projeto de Pesquisa Cep 29: núcleo capixaba de estudos da experiência humana em meio urbano, coordenado por BLANC contando com a colaboração dos estudantes de mestrado e graduação que compõem a sua equipe de pesquisadores, entre eles, Fabio Rodrigues. Paralelamente, ambos os autores realizaram coletas de dados para seus planos individuais de pesquisa, aqui articulados na elaboração da análise proposta. Igualmente, ambos os autores foram responsáveis pela elaboração deste texto, inicialmente com a articulação do debate desenvolvido por Fabio Rodrigues em sua dissertação de mestrado (orientada ao longo dos primeiros 20 meses por BLANC).

\section{Recebido em}

maio de 2020

Aprovado em

junho de 2021 